\title{
A etnografia como ferramenta para pensar e agir em saúde: reflexões sobre os problemas de pressão
}

\author{
Ethnography as a tool for thinking and acting on health: \\ reflections on blood pressure problems
}

La etnografía como herramienta para pensar y actuar en salud: reflexiones sobre los problemas de presión

DESCONTROLADA: UMA ETNOGRAFIA DOS PROBLEMAS DE PRESSÃO. Fleischer S. São Carlos: EdUFSCar; 2018. 261 p. ISBN 978-857600-499-8.

doi: 10.1590/0102-311X00019720

O livro apresenta anos de vivência e reflexão sobre um problema comum no mundo: os problemas de pressão. A autora mergulha nas realidades da comunidade Guariroba, na cidade administrativa mais populosa do Distrito Federal, Ceilândia. Realidades, no plural, pois foram seis anos de trabalho de campo, conhecendo e vivenciado o cotidiano dos moradores 1 .

Conhecer a fundo as realidades é uma característica comum da etnografia. Por meio dela, há uma troca de saberes entre o pesquisador e o universo de significância dos pesquisados, que guiam a pesquisa, que mostram caminhos a serem percorridos e nos dão novos significados. Diversos autores têm demonstrado a potencialidade da etnografia como forma de fazer ciência para a melhoria das políticas públicas ou das ações em saúde 2,3. Acima de tudo, a bibliografia aponta para a etnografia como ferramenta importante para pensar e fazer saúde, tendo como um bom exemplo o livro Descontrolada: Uma Etnografia do Problemas de Pressão 1.

No início do livro, abordam-se o percurso metodológico desenvolvido e como foi cons- truída a identidade da pesquisa. O livro também retrata como a pesquisa foi conhecida e reconhecida pelas mulheres, profissionais de saúde e estudantes da Faculdade de Ceilândia, Universidade de Brasília. É importante destacar o local de fala da autora, que demonstra por diversas vezes a dificuldade de interagir com os sujeitos, sendo considerada uma mulher privilegiada. É interessante perceber também como, aos poucos, pré-conceitos foram se desconstruindo e dando espaço para o diálogo, sendo essa a maior riqueza da pesquisa etnográfica.

A particularidade da narrativa etnográfica desloca a linearidade da escrita científica, visto que, nem sempre, os achados de pesquisa são tratados como tradicionalmente se percebe em um paper, especialmente na área da saúde. Um bom exemplo disso é a caracterização pela autora do “problema de pressão” no feminino - “ela”. Uma constatação etnográfica, ou seja, vista a partir da perspectiva das senhoras moradoras da Guariroba, fez com que a autora optasse por esse uso. Ao longo do livro, vamos percebendo que a "descontrolada” pressão apresentava características de mulheres que muitas vezes eram vistas como incapazes de controlar suas ações.

Partindo dos locais de fala, o segundo capítulo traz uma contextualização de como se criou a Guariroba, dando visibilidade para uma região negligenciada no cenário do Distrito Federal. Conhecer essa história é formar uma linha do tempo de como esses problemas de pressão apareceram. É interessante perceber que as histórias 
de migração são semelhantes umas às outras, considerando a cor de pele e a classe social dessas mulheres, que lutaram cada dia para cuidar de uma casa, cuidar dos filhos, batalhar pelos seus sonhos e, ao final de sua trajetória, lidar com os problemas da velhice.

É importante destacar dois conceitos intensamente trabalhados no livro. Um deles diz respeito à escolha do termo "problemas de pressão" em vez do termo "hipertensão arterial sensível". Enquanto o primeiro está na vida cotidiana, nas conversas de vizinhas, famílias ou nas igrejas, o segundo parte dos profissionais de saúde, demonstrando um cabo de guerra que detalharemos em seguida. O outro conceito é o de “doenças compridas”, e não "doenças crônicas". A autora detalha a razão do uso do termo "doenças compridas" a partir do reconhecimento dos indivíduos que, muitas vezes, não concordavam com o diagnóstico que recebiam do médico. O termo demonstra que os problemas de pressão eram percebidos como momentâneos, podendo ir e vir quando quisessem, deixando clara a razão de ser "comprida".

No capítulo 3, começa-se a discorrer sobre o cabo de guerra indicado anteriormente, o que pode ser considerado o coração do livro aqui resenhado. Os profissionais da saúde, que têm seus treinamentos em bases biomédicas, ditam às pessoas como devem cuidar das suas vidas, da sua alimentação, do seu modo de viver, partindo do pressuposto de que são detentores de todos os saberes. Além disso, associam o aparecimento e/ou a manutenção dos problemas de pressão a fatores de estilos de vida: "a senhora não fecha boca”. Ao contrário, as pessoas que vivenciam os "problemas de pressão" significam essa experiência de forma distinta.

As interlocutoras da etnografia apresentam diversas explicações para os problemas de pressão, como razão hereditária, problemas de gravidez, outros problemas de saúde do envelhecimento, má conduta médica, entre outras. Contudo, a explicação mais comum é a "agonia, a preocupação, a chateação" 1 (p. 101), que dão origem a picos de pressão, associados ao fator emocional. Assim, a autora indica que o cuidado com a pressão é como um cabo de guerra, entre medidas para baixá-la e os inesperados aconte- cimentos que a aumentam. É desse contexto que surge a metáfora do cabo de guerra, embora consideremos que o cabo de guerra cotidiano não é apenas a própria pressão, mas o próprio mundo biomédico no qual estamos inseridos.

É importante destacar que muitas interlocutoras que recebiam o diagnóstico de hipertensão não tomavam medicamentos específicos para a condição, mas psicotrópicos para se "acalmarem”. Isso demonstra mais uma vez que os problemas de pressão são mais complexos do que simples "estilo de vida" indicado em consultas médicas e que sua principal causa seriam os "nervos" e outras questões multifatoriais da vida. Enquanto a narrativa dos profissionais de saúde e das pessoas com problemas de pressão estiver em polos opostos do cabo de guerra, será difícil pensar em ações efetivas para o controle de morbidade $\mathrm{e}$ mortalidade de doenças cardiovasculares.

O capítulo 4 realiza uma descrição das trajetórias das interlocutoras no serviço de saúde ("postinho"), desde sua entrada até a dispensação do medicamento. Nesse capítulo, há diversos momentos de incômodo, a forma de acolhimento, a troca de informações, a baixa resolutividade e a "cultura da falta". Destaca-se que a Política Nacional de Humanização, de 2003, já indica como acolher e escutar as pessoas que chegam a qualquer ponto de atenção do Sistema Único de Saúde (SUS).

Percebe-se que o grupo de acolhimento oficial se utilizava de estratégias que retomavam o conhecimento hegemônico dos profissionais de saúde, desconsiderando os saberes dos indivíduos. A etnografia demonstra que os grupos realmente de apoio eram aqueles formados nos corredores, com trocas de receitas, dietas, convites para eventos, explicações de por que suas pressões estavam descontroladas, dicas de que remédios pedir para as médicas etc. Tudo isso ocorria enquanto aguardavam suas consultas semestrais.

Ignorar os saberes dos indivíduos que vivenciam o dia a dia dos problemas de pressão é realizar um trabalho que dificulta a implementação da política pública. Não devemos atribuir toda a responsabilidade aos profissionais de saúde que realizam os atendimentos. Contudo, percebe-se que há um paradoxo no SUS, em que os saberes 
biomédicos são sobrepostos aos populares, em que os profissionais reproduzem suas vivências da cultura da "falta" e externalizam as dificuldades cotidianas dos serviços na relação com os usuários.

Pensar como efetivar uma política não é simplesmente olhar para os números de indicadores padronizados de sistemas de saúde, mas perceber atentamente as diferentes formas de vivenciar e interpretar determinadas normativas e de vivenciar as questões de saúde. É olhar para os contextos e considerar o que vem deles. É produzir mais etnografias em saúde para instrumentalizar políticas públicas.

Indyara de Araujo Morais 1,2

Éverton Luis Pereira 1

1 Universidade de Brasília, Brasília, Brasil.

2 Ministério da Saúde, Brasília, Brasil.

indydymorais@gmail.com

\section{Colaboradores}

Os autores participaram conjuntamente da redação da resenha.

\section{Informações adicionais}

ORCID: Indyara de Araujo Morais (0000-00016662-0788); Éverton Luís Pereira (0000-00027771-1594).

\section{Referências}

1. Fleischer S. Descontrolada: uma etnografia dos problemas de pressão. São Carlos: EdUFSCar; 2018.

2. Trad LAB. Trabalho de campo, narrativa e produção de conhecimento na pesquisa etnográfica contemporânea: subsídios ao campo da saúde. Ciênc Saúde Colet 2012; 17:627-33.

3. Caprara A, Landim LP. Etnografia: uso, potencialidades e limites na pesquisa em saúde. Interface Comun Saúde Educ 2008; 12:363-76. 